DOI 10.37882/2500-3682.2021.09.11

\title{
ЭМПИРИЧЕСКОЕ ИССЛЕДОВАНИЕ КОМПОНЕНТОВ И ФАКТОРОВ ЖИЗНЕСПОСОБНОСТИ ЖИТЕЛЕЙ СЕВАСТОПОЛЯ 1
}

\section{EMPIRICAL STUDY OF COMPONENTS AND FACTORS OF RESILIENCE OF SEVASTOPOL RESIDENTS}

\section{S. Nalichaeva \\ A. Tkachenko \\ Z. Borisenko \\ B. Terentyev \\ E. Lukina}

Summary: Resilience is an individual ability to manage in the context of cultural norms, environmental conditions and society with its resources and includes a number of components: self-efficacy, persistence, coping and adaptation, locus of control, spirituality, family and social relationship. Resilience promotes burnout and stress resistance. Purpose of the study: to analyze the factors of the resilience of the inhabitants of Sevastopol. The article describes the results indicating that the indicators of the components of resilience differ depending on age, type of culture, marital status, profession. The features of the manifestation of burnout in representatives of different age groups are described. Such manifestations as unconstructive coping and low assertiveness hinder the development of resilience, and a low level of resilience can be a predictor of the development of burnout symptoms. Resilience determines the resistance to burnout. It was obtained that the factor space of 8 factors, explaining $87 \%$ of the variance and describing the structure of resilience: «Internal and external activity of the subject», "Activity in achieving the goal, as an indicator of resilience - passivity, as a manifestation of burnout», «Aspiration help others, the strength of the soul is the experience of traumatic circumstances», "Competition, confidence, «Burnout as nonconstructive coping", "Constructive prosocial coping - non-constructive coping associated with the economy of emotions», "The desire to do good", "Courage and the desire to understand others - selective emotional response». The experience of traumatic circumstances manifests itself with insufficiently developed components of resilience, and is a key symptom of burnout of subjects with a low resilience index.

Keywords: resilience, mentality, components of resilience, factors of resilience, culture.

\author{
Наличаева София Александровна
}

К.nсх.н., доцент, Филиал Московского государственного университета имени М.В. Ломоносова в городе

Севастополе

espritsn@yandex.ru

Ткаченко Анастасия Александровна

психолог, Филиал Московского государственного университета имени М.В. Ломоносова в городе

Севастополе

anastasiyaderzhavina93@mail.ru

Борисенко Зинаида Викторовна

старший преподаватель, Филиал Московского государственного университета имени М.В. Ломоносова в городе Севастополе

bzvpost@gmail.com

Терентьев Богдан Игоревич

Филиал Московского государственного университета имени М.В. Ломоносова в городе Севастополе

tbogdan@mail.ru

Лукина Екатерина Максимовна

Филиал Московского государственного университета имени М.В. Ломоносова в городе Севастополе lookinaketrin21@yandex.ru

Аннотация: Жизнеспособность является индивидуальной способностью к управлению своими ресурсами и включает в себя ряд компонентов: самоэффективность, настойчивость, совладание и адаптацию, локус контроля, духовность, семейные и социальные взаимоотношения. Жизнеспособность способствует резистентности к синдрому выгорания и стрессу. Цель исследования: проанализировать факторы жизнеспособности жителей Севастополя. В статье описаны результаты, указывающие на то, что показатели компонентов жизнеспособности различаются в зависимости от возраста, типа культуры, семейного положения, профессии. Описаны особенности проявления выгорания у представителей разных возрастных групп. Препятствуют развитию жизнеспособности такие проявления, как неконструктивный копинг и низкая ассертивность, а низкий уровень жизнеспособности может быть предиктором развития симптомов выгорания. Жизнеспособность детерминирует устойчивость к выгоранию. Получено факторное пространство из 8 факторов, объясняющее 87 \% дисперсии и описывающее структуру жизнеспособности: «Внутренняя и внешняя активность субъекта», «Активность в достижении цели, как показатель жизнеспособности - пассивность, как проявление выгорания», «Стремление помогать окружающим, сила души переживание психотравмирующих обстоятельств», «Соревновательность, уверенность», «Выгорание, как неконструктивный копинг», «Конструктивый просоциальный копинг - неконструктивный копинг, связанный с экономией эмоций»; «Стремление делать добро», «Смелость и стремление понимать

1 Исследование выполнено при финансовой поддержке РФФИ и Правительства города Севастополя. Проект «Ментальность как компонент жизнеспособности жителей Севастополя», № 20-413-920002 p_a 


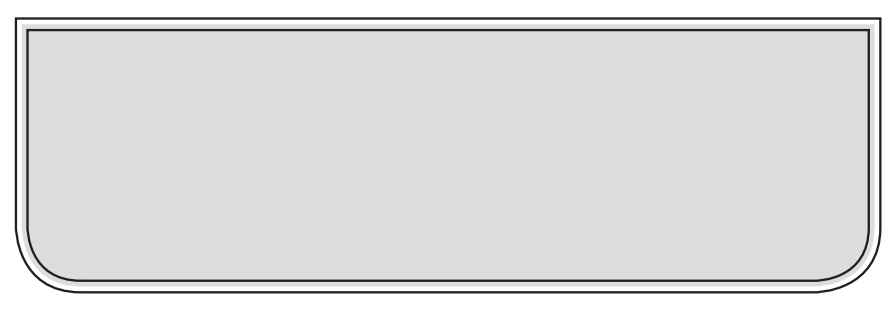

Введение

A ктуальность проблемы определяется тем, что в современном мире, в условиях неопределенности, человек испытывает влияние стресс-факторов среды: физических, психологических, информационных, эпидемиологических. Анализ теоретических данных показал, что компоненты жизнеспособности рассмотрены в работах различных авторов (А.В. Махнач, Е.А. Рыльская, А.А. Нестерова), проанализировано соотношение понятий жизнестойкости и жизнесопосбности (показаны их различия) (А.В. Махнач, Л.Г. Дикая, А.И. Лактионова, Е.А.Рыльская), рассмотрена связь жизнеспособности с совладанием и адаптацией (Л.Г. Дикая, И.А. Курапова), рассмотрены подходы к изучению ментальности в психологии (Г.В. Акопов, А.Ю. Горбенко, Е.В. Демина, Г.Ф. Иванова, Г.У. Солдатова, Е.В. Емельянова и др.), как компонента жизнеспособности и связи ментальности с жизнеспособностью (С.А. Хазова, Т.А. Нестик, А.В. Махнач). С опорой на исследования этих ученых в данной статье проанализированы компоненты и факторы жизнеспособности, описано факторное пространство показателей жизнеспособности, выгорания и ментальности. Полученные данные важны с практической точки зрения в аспекте формирования и развития жизнеспособности. Жизнеспособность является индивидуальной способностью к управлению в контексте культурных норм, условий среды и социума своими ресурсами [1], к компонентам жизнеспособности можно отнести ментальность и культуру человека (его созидательный, творческий потенциал) [2], [3], [4]. Основными факторами развития субъекта в процессе овладения созданным человечеством миром культуры являются активная предметнопрактическая деятельность, общение и познание [5]. В данном исследовании компоненты жизнеспособности рассматриваются согласно авторской многокомпонентной модели жизнеспособности. В рамках данной модели одним из центральных компонентов жизнеспособности является ментальность, жизнеспособность базируется на индивидуальности, субъектности, личностном самоактуализационном потенциале (ЛСП). Индивидуальность включает в себя свойства на уровне организма, психические и социально-психологические свойства. Субъектность включает в себя активность, автономность, целостность. В состав ЛСП входят мотивы, ценности и смыслы. Культура, общество, личность и отношения влияют на жизнеспособность человека. Высокие других - избирательное эмоциональное реагирование». Переживание психотравмирующих обстоятельств проявляется при недостаточно развитых компонентах жизнеспособности, и является ключевым симптомов выгорания испытуемых с низким показателем жизнеспособности.

Ключевые слова: жизнеспособность, ментальность, компоненты жизнеспособности, факторы жизнеспособности, культура.

показатели жизнеспособности соотносятся с адаптацией, развитием и самоактуализацией, а низкие показатели жизнеспособности могут вести к стрессу, болезнями и синдрому выгорания. А.В. Брушлинский развил представления о субъекте, закрепив за категорией субъекта системообразующую роль в психологической науке. Субъект - человек, люди на высшем (индивидуализированно для каждого) уровне активности, целостности (системности), автономности. Окружающий мир для субъекта не просто набор сигнальных раздражителей, а объект действия и познания, а другие люди представляются тоже как субъекты [6]. Любой человек не рождается, а становится субъектом в процессе своей деятельности, общения и других видов активности. В целом развитие субъектности характеризуется тенденцией выделения человеком себя из «фона» окружающей действительности, соотносимой с развивающейся способностью к рефлексии своей нерядоположенности с объектами среды, отражающей понимание собственной способности заявлять о себе и проявлять себя в этом мире. Уверенность в себе, самоконтроль, вера в свои силы, воля позволяют человеку сформировать активную жизненную позицию, при которой человек ощущает себя инициирующим началом. В профиле жизнеспособного человека ярко выражены такие качества, как выносливость, стабильная самооценка, альтруизм, самораскрытие, представление о себе как о личности, преодолевшей стресс. Семья выполняет важную функцию поддержки и защиты. Семья имеет в своей основе множество функций, отвечающих не только за моральное и эмоциональное состояние ее членов, но и за воспитание детей, сохранение и передачу культурных традиций, материальных благ. Индивидуально-динамические характеристики темперамента являются фактором развития семейного самоопределения юношей и девушек [7]. А.С. Миловановой получено, что юноши более склонны проявлять притязания на семейную жизнь, чем девушки, важными для них сферами реализации семейных отношений является социальная активность, эмоциональная поддержка, которую они также ожидают получать от своего партнера. Выявлено множество характеристик семейных отношений, способствующих преодолению неблагоприятных ситуаций: положительные методы воспитания, связь с родителями, низкий уровень конфликтности между родителями, родительский контроль, ясные модели семейного общения, последовательность в заботе и дисциплина, эмоциональная близость между членами семьи и умение под- 
держивать отношения с родителями на протяжении всей жизни. Жизнеспособность является одним из важнейших ресурсов развития человека, условием социальной адаптации, саморегуляции, самоактуализации [8]. Кроме этого, составляющими жизнеспособности человека являются нравственность, духовность, ментальность и культура. Под ментальностью в данной работе понимается относительно устойчивая совокупность установок индивида или социальной группы воспринимать мир определенным образом. Жизнеспособность выступает как потенциал сохранения целостности человека [9]. Жизнеспособность связана с понятием индивидуальности человека [10].

\section{Материалы и методы}

Цель: проанализировать факторы жизнеспособности жителей Севастополя. В исследовании использованы психодиагностические тестовые методики, направленные на диагностику жизнеспособности, проявлений дезадаптации (синдрома выгорания): Тест жизнеспособности человека (А.В. Махнач, 2016); Диагностика эмоционального выгорания личности (В.В. Бойко, 2002); Тест культурно-ценностных ориентаций (Дж. Таусенд, Л.Г. Почебут, 2004); Опросник для создания индивидуального культурного профиля (Г.У. Солдатова, Л.А. Шайгерова, А.В. Макарчук, 2009).

Изучение ментальности в психологии предполагает использование комплекса методов и методик в рамках номотетического и идеографического подхода. Исключительно номотетический подход предполагает установление закономерности в формировании и проявлении ментальности у групп людей, количественный анализ ее показателей, тогда как охватить спектр индивидуальных различий в проявлении ментальности при помощи тестового метода не представляется возможным. Разработать психодиагностический тест для оценки ментальности крайне сложно, так как он задает определенную схему в описании ментальности, основанную на субъективном понимании автора. В связи с этим, использование качественного анализа при исследовании индивидуальных особенностей ментальности человека является более информативным. Реализовать идеографический подход при диагностике и описании ментальности возможно, используя метод анкетирования. Для диагностики ментальности была разработана анкета, позволяющая описать особенности ментальности, как сложного психологического феномена с заявленных теоретических позиций. В авторскую анкету вошли вопросы о социально-демографических характеристиках, особенностях отношения к своему городу, жителям города и себе, особенностях межличностного восприятия, ценностях, смыслах, отношении ко времени и деятельности, своему прошлому, настоящему и будущему. Полученные данные обработаны с использованием методов матема- тической статистики с применением анализа средних значений, частот и факторного анализа. Всего в исследовании приняло участи 320 человек (126 мужчин и 194 женщины, в возрасте от 18 до 61 года).

\section{Результаты}

В результате исследования получено, что в профиле жизнеспособности жителей Севастополя преобладают настойчивость и семейные взаимосвязи, наименее характерны - духовность и вера, что может говорить о том, что им свойственны желание и способность к борьбе за баланс, вопреки неблагоприятным воздействиям, упорство и поиск социальной поддержки в кругу семьи и друзей. Респонденты не склонны обращаться к «высшей силе» в трудных жизненных обстоятельствах, полученные данные соотносятся с достаточно высокими уровнями внутреннего локуса контроля. Высокие показатели локуса контроля говорят о способности испытуемых нести ответственность за свои действия, осознавать свою активность и ответственность за события жизни, свое состояние, отношения, и результаты своей деятельности, видеть и осознавать причинно-следственные связи, не рассчитывая на внешние или высшие силы в решение жизненных задач.

Исследование, проведенное при помощи авторской анкеты, позволило описать некоторые особенности ментальности жителей Севастополя. По мнению респондентов, севастопольцев характеризует неторопливость, общительность, равнодушие, спокойствие, размеренность, оптимизм, отзывчивость, патриотизм, воспитанность, активность, гордость, легкость, доброжелательность, воспитанность, уважение друг к другу. В молодом возрасте наиболее выражены качества: стремление к достижению успеха, в возрасте от 23 до 35 лет наименее выражены такие качества, как умение ограничивать себя, замкнутость, настойчивость, предприимчивость. Для испытуемых в возрасте от 36 до 49 лет наиболее характерны общительность, оптимизм, уверенность в себе, добросовестность, умение сочувствовать, сострадать, потребность делать добро, трудолюбие. В наиболее старшей подгруппе выборки испытуемыми получены высокие оценки таких качеств, как: порядочность, готовность прийти на помощь, добросовестность, доброжелательность, целеустремленность, стремление быть с родными, осуществление смысла жизни. Не выявлено различий у мужчин и женщин в оценивании качеств.

\section{Возрастные особенности жизнеспособности}

В результате диагностики компонентов жизнеспособности у испытуемых разных возрастных групп получено, что наиболее выражены у всех испытуемых такие компоненты, как самоэффективность, настойчивость, локус контроля, совладание и адаптация, семейные взаимоот- 
ношения. Наименьшие показатели компонентов жизнеспособности получены в группе молодежи (от 18 до 22 лет). Более выражены компоненты жизнеспособности в старшей группе (от 50 до 61 года). Наиболее выражены компоненты жизнеспособности у испытуемых в возрасте от 23 до 35 лет и в возрасте от 36 до 49 лет. Не выявлено различий в компонентах жизнеспособности между подгруппами от 23 до 35 лет и в возрасте от 36 до 49 лет. Выявлены статистически значимые различия между младшей подгруппой и остальными подгруппами во всех компонентах жизнеспособности $(p<0,01)$. В профиле жизнеспособности в группе испытуемых в возрасте от 18 до 22 лет преобладают самоэффективность, совладание и адаптация, а менее выражены настойчивость, локус контроля, семейные взаимоотношения, наименее выражен компонент духовности. Полученные данные подтверждаются установленной корреляционной связью между возрастном и жизнеспособностью $(r=0,4$, при $\mathrm{p}<0,01)$, то есть чем старше респонденты, тем выше у них показатель жизнеспособность, по результатам данной выборки.

\section{Профессия и жизнеспособность}

В исследовании приняли участие представители разных профессий: преподаватели вуза, учителя, психологи, инженеры, предприниматели, экономисты, программисты, юристы, военнослужащие, врачи, художники, участвовали в исследовании студенты и безработные. Профессиональная деятельность является важной для развития личности человека, личное и профессиональное самоопределение связаны между собой. Профессия обогащает личность и формирует у человека много положительных качеств, однако могут развиваться и негативные явления под влиянием профессии, такие как профессиональные деструкции и деформации, в том числе и синдром выгорания. Анализ показателей компонентов жизнеспособности у представителей разных профессий показал, что у преподавателей вуза, врачей, художников наиболее выражены показатели жизнеспособности, у всех профессиональных групп наиболее выражены семейные взаимоотношения и самоэффективность, локус контроля, наименее выражена у всех профессиональных групп духовность и вера.

\section{Семейное положение и жизнеспособность}

Анализ средних значений компонентов жизнеспособности у представителей подгрупп, выделенных по семейному положению, показал, что наибольшие показатели по всем компонентам жизнеспособности выявлены у подгруппы «женат/замужем», показатели компонентов жизнеспособности значимо ниже у подгруппы «не женат/не замужем», самые низкие показатели по компонентам жизнеспособности выявлены у молодежи, живущей с родителями. Семейное положение является значимой детерминантой психологического состояния человека, так было показано в данном исследовании, что семейное положение связано с уровнем выгорания, у семейных испытуемых уровень тревожного напряжения ниже, чем у тех, кто живет отдельно от родителей и не имеет своей семьи или пары.

\section{Пол и жизнеспособность}

У мужчин и женщин в целом, все показатели жизнеспособности представлены на одном уровне, кроме показателя духовности. Не выявлено различий в проявлении компонентов жизнеспособности у женщин и мужчин. Интересно, что переменная пола не выступила дифференцирующей, но по симптомам и фазам выгорания, ни по компонентам жизнеспособности.

\section{Время прожкивания в Севастополе}

Анализировались средние показатели компонентов жизнеспособности в подгруппах, выделенных по времени проживания в Севастополе: от 1 до 5 лет; от 6 до 10 лет; от 11 до 15 лет; от 16 до 20 лет; более 21 года.

Между подгруппами не выявлено различий по компонентам жизнеспособности кроме показателей подгруппы проживающих в Севастополе более 21 года, показатели данной подгруппы несколько выше показателей других подгрупп.

\section{Культурный профиль и жизнеспособность}

На основе диагностики при помощи теста культурноценностных ориентаций получено пять подгрупп испытуемых:

1 подгруппа - традиционная культура (ТК): характеризуется ориентацией на прошлое, традиции, интерес к истории, зависимостью от социального окружения, семейных связей, родственных ролевых отношений, религиозных ориентаций;

2 подгруппа - современная культура (СК): характеризуется ориентацией людей на настоящее, на современные события, ценности этой культуры сосредоточены на человеке, его правах, призвании;

3 подгруппа - традиционная и современная культуры (ТК-СК): сочетание ориентаций традиционной и современной культуры;

4 подгруппа - динамически развивающаяся культура (ДРК): характеризуется ориентацией людей на будущее, на достижение быстрых значительных результатов, люди строят краткосрочные планы и стараются реализовать их как можно более энергично, признается значимость 
индивидуальных интересов и ценностей;

5 подгруппа - современная культура и динамически развивающаяся культура (СК-ДРК) сочетает в себе ориентации современной и динамически-развивающейся культуры.

Получено, что самоэффективность наиболее выражена у подгруппы с традиционной культурой, современной культурой, наименьший показатель самоэффективности выявлен у подгруппы с динамически-развивающейся культурой. По показателю настойчивости нет различий между подгруппами, кроме подгруппы с динамическиразвивающейся культурой, у которой показатель настойчивости ниже, чем в других подгруппах. По показателям локуса-контроля и семейных взаимоотношений не выявлено различий.

Показатель совладания и адаптации наиболее выражен у подгруппы с традиционной культурой, а показатель духовности у подгруппы с динамически-развивающейся культурой.

Результаты факторного анализа показателей жизнеспособности, представленные в литературе, продемонстрировали сложность и многомерность феномена жизнеспособности. После Varimax-вращения Е.А. Рыльской было выделено 5 базовых факторов, которые охватывают 61,48 \% совокупной дисперсии, что свидетельствует об их достаточной, хотя и сравнительно невысокой информативности. Ни у одного из факторов не был выражен отрицательный полюс, что заметно затруднило интерпретацию. Относительно невысокими оказались и факторные нагрузки [11]. Согласно полученным автором данным, в структуре жизнеспособности выделены следующие факторы: «осознанное жизнелюбие», «самоактуализационный», «адаптация», «реализующий жизненную программу», «коммуникабельность».

В отличие от результатов, полученных Е.А. Рыльской, выделено, в результате факторизации показателей ментальности, жизнеспособности, синдрома выгорания, пространство из 8 факторов, объясняющее 87 \% дисперсии.

В первый фактор «Внутренняя и внешняя активность субъекта» (21\% дисперсии) вошли: духовность $(0,60)$, осуществление смысла в жизни (стремление к пониманию смысла) $(0,82)$, религиозность $(0,59)$, вера $(0,81)$, привычка жить сегодняшним днем $(-0,55)$, азарт $(-0,53)$, разграничение личного и профессионального $(0,91)$, деловитость $(-0,85)$, замкнутость $(0,88)$, настойчивость $(-0,90)$, предприимчивость $(0,78)$, смелость $(0,91)$, коммуникативный стиль $(-0,73)$, отношения между партнерами $(-0,73)$. На одном полюсе фактора расположились духовные качества человека, замкнутость, а на противо- положном - активные проявления, деловитость, смелость, настойчивость, то есть человек может черпать ресурсы жизнеспособности из своего духовного мира или в большей степени за счет коммуникаций, смелости, предприимчивости и настойчивости. С одной стороны, обращение к своим внутренним ресурсам и их актуализация представляет важный фактор жизнеспособности, а с другой стороны, смелость с реализации своего потенциала также играет важную роль в формировании жизнеспособности. При анализе компонентов жизнеспособности стоит учитывать эти особенности (биполярный фактор, определяющий внутреннюю и внешнюю активность человека в жизни и деятельности при реализации планов и достижении поставленных целей).

Во второй фактор «Активность в достижении цели, как показатель жизнеспособности - пассивность, как проявление выгорания» (18\% дисперсии) вошли: самоэффективность $(0,71)$, настойчивость $(0,57)$, локус контроля $(0,47)$, добросовестность $(0,51)$, скромность $(-0,56)$, потребность в чуде $(0,89)$, жажда приключений $(0,79)$, любовь к праздникам $(0,82)$, стремление к достижению успеха $(0,66)$, решительность $(0,56)$, трудолюбие $(0,53)$, «загнанность в клетку» $(-0,80)$, тревога и депрессия $(-0,75)$, фаза «Тревожное напряжение» $(-0,82)$, эмоциональная отстраненность $(-0,55)$, дистанция власти $(0,78)$, отношение к коллективу $(0,77)$, избегание неопределенности $(0,62)$, ориентация во времени $(0,52)$. Данный фактор отражает противоположность выгорания и жизнеспособности, так на одном полюсе фактора расположились самоэффективность, проявления ассертивности и стремление к достижению успеха, а на противоположном полюсе - проявления синдрома выгорания. Важным компонентом жизнеспособности является активность в достижении цели (что соотносится с настойчивостью), так активность, направленная на достижение цели, обычно подкрепляется позитивными эмоциями и пиковыми переживаниями в результате достижения значимой цели. При интерпретации данного фактора интересным является, то, что выгорание является противоположным активности явлением, что соотносится с представлением К. Маслач о биполярном факторе выгорания, где на одном полюсе - выгорание, а на другом вовлеченность.

В третий фактор «Стремление помогать окружающим, сила души - переживание психотравмирующих обстоятельств» (13\% дисперсии) вошли готовность прийти на помощь $(0,56)$, порядочность $(0,87)$, доброжелательность $(0,70)$, любовь к переменам $(0,56)$, переживание психотравмирующих обстоятельств $(-0,66)$. В данном факторе выделились два полюса: на одном полюсе стремление помогать, как проявление силы души и жизнеспособности, а на противоположном - симптом выгорания, отражающий упадок сил, тяжелые переживания и проявление дезадаптации. Стремление помогать, про- 
явление доброты, эмпатичности, наивысших душевных качеств - значимый фактор жизнеспособности. Симптом выгорания, связанный с переживанием психотравмирующих обстоятельств, отражает тревожность и недоверие к миру, рассмотрение широкого спектра ситуаций и раздражителей, как угрожающих и ведущих к стрессу, пугающих, подкрепляющих недоверие.

В четвертый фактор «Соревновательность, уверенность в себе» (9\% дисперсии) вошли уверенность в себе $(0,62)$, стремление рисковать $(0,66)$, надежда на удачу $(0,66)$, соревновательность $(0,65)$. В пятый фактор «Выгорание, как неконструктивный копинг» (8\% дисперсии) вошли: эмоционально-нравственная дезориентация $(-0,74)$, редукция профессиональных обязанностей $(-0,89)$, фаза «Резистенция» $(-0,93)$, личностная отстраненность (деперсонализация) (-0,56), психосоматические и психовегетативные нарушения $(-0,69)$, фаза «Истощение» $(-0,84)$. Данный фактор отражает неконструктивный копинг и проявление дезадаптации: снижение ответственности, профессиональная стагнация, отношение к другому человеку, как к объекту, а не субъекту, наделенному индивидуальностью, изменения в эмоциональной сфере, ухудшение здоровья и психического состояния.

В шестой фактор «Конструктивый просоциальный копинг - неконструктивный копинг, связанный с экономией эмоций» (7\% дисперсии) вошли: совладание и адаптация $(0,60)$, семейные и социальные взаимоотношения $(0,54)$, оптимизм $(0,83)$, общительность $(0,56)$, целеустремленность $(0,71)$, стремление быть с родными людьми $(0,84)$, неудовлетворенность собой $(-0,48)$, расширение сферы экономии эмоций $(-0,64)$, эмоциональный дефицит $(-0,56)$. Интересным представляется то, что выделены два фактора, отражающие конструктивный и неконструктивный копинг.

В седьмой фактор «Стремление делать добро» (5\% дисперсии) вошли: умение сочувствовать, сострадать $(0,57)$, потребность делать добро $(0,44)$. В структуре жизнеспособности выделяется стремление делать добро, как проявление жизнеспособности.

В восьмой фактор «Смелость и стремление понимать других - избирательное эмоциональное реагирование» (4\% дисперсии) вошли: достижения блага для окружающих $(0,65)$, стремление понимать других $(0,54)$, смелость $(0,62)$, неадекватное избирательное эмоциональное реагирование $(-0,61)$. Выделился фактор, отражающий на одном полюсе смелость и стремление понимать других, активность в социальных контактах, просоциальные тенденции, а на другом - избирательное эмоциональное реагирование (эмоциональная скованность, эмоциональное реагирование на все меньший спектр ситуаций и взаимодействий). Таким образом, препятствуют развитию жизнеспособности такие проявления, как некон- структивный копинг и низкая ассертивность, а низкий уровень жизнеспособности может быть предиктором развития симптомов выгорания, например, переживания психотравмирующих обстоятельств и расширения сферы экономии эмоций.

Для человека, обладающего развитой жизнеспособностью, характерны развитые внутренние ресурсы, духовные качества и активные проявления, связанные с их реализацией, активность, субъектность, стремление к цели и ее достижение, доброта, стремление помогать, смелость в установлении контактов, отзывчивость, доброжелательность, умение отстоять себя, свои взгляды, умение побеждать, уверенность в себе, оптимизм, стремление к семейным и социальным контактам, поиск социальной поддержки, умение сочувствовать, стремление понимать других, их чувства и эмоции.

Для человека с низкой жизнеспособностью характерны следующие особенности: проявления синдрома выгорания, стресса, неконструктивный копинг, связанный с экономией эмоций и изменениями в эмоциональной и коммуникативной сферах личности, избегание, обесценивание окружающих, своей профессиональной деятельности, пассивность, переживание психотравмирующих обстоятельств, психосоматические и психовегетативные проявления, безразличие к людям, отсутствие стремления делать добро и понимать других.

\section{Выво $\Delta ы$}

Показатели компонентов жизнеспособности различаются в зависимости от возраста, типа культуры, семейного положения, профессии. Получено, факторное пространство, описывающее структуру жизнеспособности: «Внутренняя и внешняя активность субъекта», «Активность в достижении цели, как показатель жизнеспособности - пассивность, как проявление выгорания», «Стремление помогать окружающим, сила души переживание психотравмирующих обстоятельств», «Соревновательность, уверенность», «Выгорание, как неконструктивный копинг», «Конструктивый просоциальный копинг - неконструктивный копинг, связанный с экономией эмоций»; «Стремление делать добро», «Смелость и стремление понимать других - избирательное эмоциональное реагирование». Высокий уровень жизнеспособности и личностного самоактуализационного потенциала способствуют резистентности к выгоранию. Ментальность является основополагающим компонентом жизнеспособности. Жизнеспособность человека соотносится с его самоактуализационным потенциалом, в который входят ценности, смыслы и мотивы. Личностный самоактуализационный потенциал выступает основой резистентности к выгоранию и способствует жизнеспособности, определяя ценностное отношение к жизни и профессии, к окружающим, к общению и познанию. 


\section{ЛИТЕРАТУРА}

1. Махнач А.В. Исследование жизнеспособности человека: основные подходы и модели // Жизнеспособность человека: индивидуальные, профессиональные и социальные аспекты / Отв. ред. А.В. Махнач, Л.Г. Дикая. - М.: Изд-во «Институт психологии РАН», 2016. - С. 46-70.

2. Наличаева С.А., Борисенко 3.В., Лукина Е.М., Терентьев Б.И., Ткаченко А.А. Анализ компонентов жизнеспособности у молодежи города Севастополя // Семья и личность: проблемы взаимодействия, 2020. - № 17. - С. 87-94

3. Махнач А.В. Жизнеспособность человека и семьи: социально-психологическая парадигма. М.: «Институт психологии РАН», 2016. - С.135-204.

4. Lazarus R.S., Folkman S. The concept of coping // Stress and Coping: An anthology / A. Monat, R.S. Lazarus (Eds). New York: Columbia University Press, 1991. P. $189-206$.

5. Сайко Э.В. Субъект действия в реализации «сознательного существования бытия» и формировании исторического содержания социальной эволюции / Э.В. Сайко // Субъект действия, взаимодействия, познания. Психологические, философские, социаокультурные аспекты. - М.: МПСИ; Воронеж: НПО «МОДЭК», 2001. - С. 8.

6. Брушлинский А.В. 0 критериях субъекта. Психология индивидуального и группового субъекта / А.В. Брушлинский. - М.: ПЕРСЭ, 2002. - 368 с.

7. Наличаева С.А., Ткаченко А.А., Милованова А.С. Стиль семейного воспитания как фактор развития личности // Семья и личность: проблемы взаимодействия, 2018. - №11. - С. 63-70.

8. Рыльская Е.А. Жизнеспобность как потенциал целостности человека и его бытия: интегративный подход // Жизнеспособность человека: индивидуальные, профессиональные и социальные аспекты / Отв. ред. А.В. Махнач, Л.Г. Дикая. - М.: Изд-во «Институт психологии РАН», 2016. - С. 111-128.

9. Акопов Г.В., Давыдкина Л.В., Семенова Т.В. Ментальность как групповое сознание: учебное пособие по курсу «Психология ментальности»: для магистратуры по психологическим направлениям. - Самара: ПГСГА, 2015. - 76 с.

10. Мерлин В.С. Очерк интегрального исследования индивидуальности. - М.: Педагогика, 1986. - 256 с.

11. Рыльская Е.А. Психология жизнеспособности человека: Автореф. дис. ...докт. психол. наук. - Ярославль, 2014. 446 с.

( ) Наличаева София Александровна (espritsn@yandex.ru), Ткаченко Анастасия Александровна (anastasiyaderzhavina93@mail.ru), Борисенко Зинаида Викторовна (bzvpost@gmail.com), Терентьев Богдан Игоревич (tbogdan@mail.ru),

Лукина Екатерина Максимовна (lookinaketrin21@yandex.ru).

Журнал «Современная наука: актуальные проблемы теории и практики»

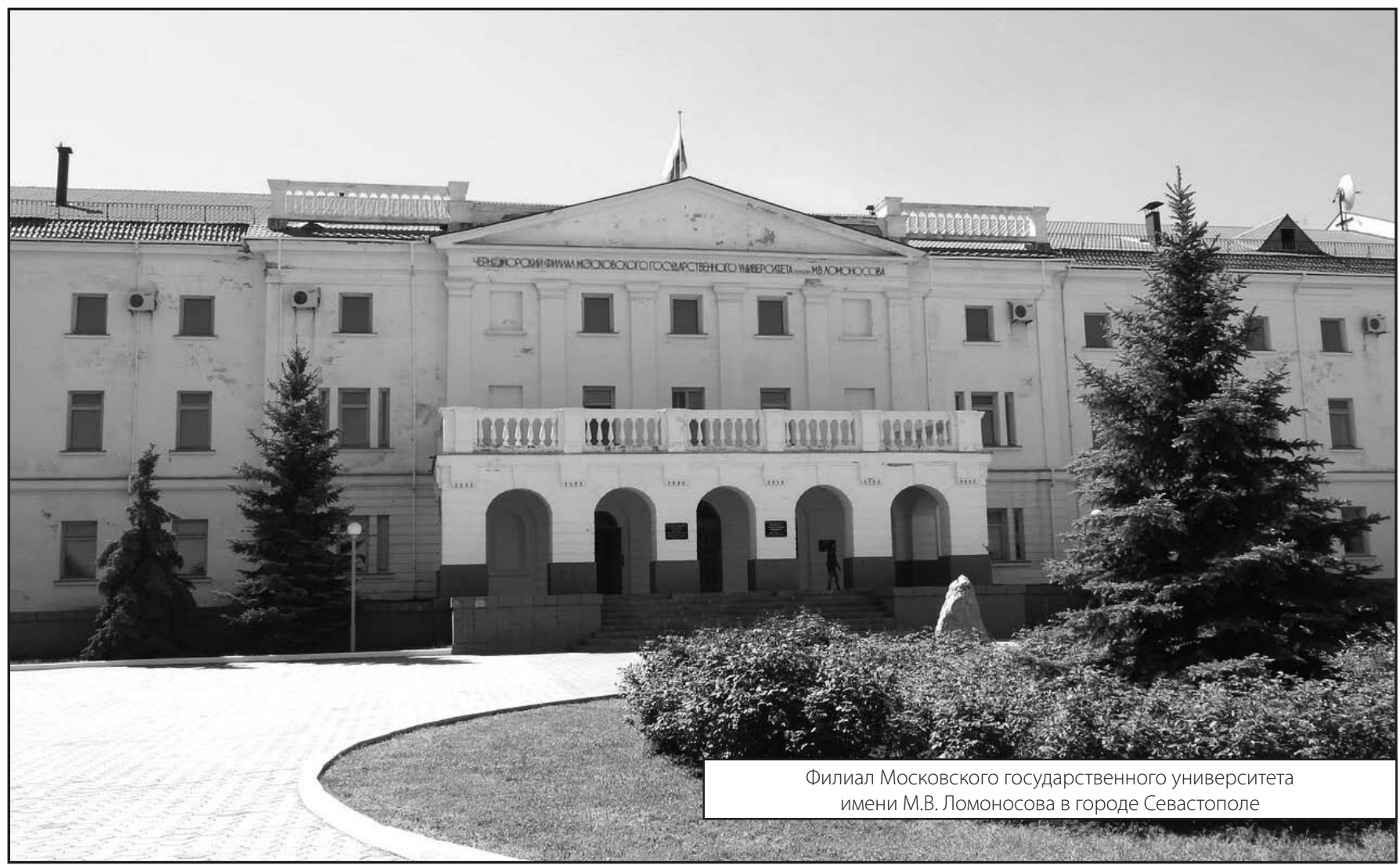

